\title{
The joint impact of habitual exercise and glycemic control on the incidence of chronic kidney disease (CKD) in middle- aged and older males
}

\author{
Ryoma Michishita ${ }^{1,2^{*}}$ (D), Takuro Matsuda ${ }^{2,3}$, Shotaro Kawakamii ${ }^{4}$ Satoshi Tanaka ${ }^{4}$, Akira Kiyonaga ${ }^{2}$, Hiroaki Tanaka ${ }^{2,4}$,
} Natsumi Morito ${ }^{5,6}$ and Yasuki Higaki ${ }^{2,4}$

\begin{abstract}
Background: This retrospective study evaluated the influence of the joint impact of habitual exercise and glycemic control on the incidence of chronic kidney disease (CKD) during a 6-year follow-up period in middle-aged and older males.

Methods: The study population included 303 males without a history of cardiovascular disease, stroke, renal dysfunction, or dialysis treatment. Their lifestyle behaviors regarding exercise and physical activity were evaluated using a standardized self-administered questionnaire. The participants were divided into four categories according to the performance or non-performance of habitual exercise and the presence or absence of hyperglycemia.

Results: After 6 years, 32 subjects (10.6\%) developed CKD (estimated glomerular filtration rate $<60 \mathrm{ml} / \mathrm{min} / 1.73 \mathrm{~m}^{2}$ and/or proteinuria). The cumulative incidence of CKD was significantly higher among subjects who did not perform habitual exercise and hyperglycemic subjects (log-rank test: $p<0.05$, respectively). According to a Cox proportional hazards model, the hazard ratio (HR) for the incidence of CKD in subjects with a normal glucose tolerance (NGT) who did not perform habitual exercise ( $H R=2.82,95 \%$ confidence of interval $(C l)=1.07-7$. $36, p=0.034)$ and that in hyperglycemic subjects who did not perform habitual exercise (HR $=5.89,95 \%$ $\mathrm{Cl}=1.87-16.63, p=0.003$ ) were significantly higher in comparison to the subjects with a NGT who performed habitual exercise.
\end{abstract}

Conclusions: These results suggest that the habitual exercise and good glycemic control and their combination were associated with the incidence of CKD.

Keywords: Incidence of CKD, Habitual exercise, Glycemic control, Health checkup

\section{Background}

The number of patients with end-stage renal disease (ESRD) in Japan is continuously increasing [1]. Chronic kidney disease (CKD) has been associated with the development of ESRD and cardiovascular disease (CVD) $[2,3]$. At present, the large number of ESRD patients is thought to be related to an increase in the number of

\footnotetext{
* Correspondence: rmichishita@med.uoeh-u.ac.jp

${ }^{1}$ Department of Health Development, Institute of Industrial Ecological

Sciences, University of Occupational and Environmental Health, Kitakyushu, Japan

${ }^{2}$ Fukuoka University Institute for Physical Activity, Fukuoka, Japan

Full list of author information is available at the end of the article
}

patients with CKD. The risk factors for CKD are reported to be caused by aging, hypertension, diabetes mellitus (DM), and metabolic syndrome [4-6]. In a recent study, we found that hypertension and hyperglycemia alone and in combination are independent risk factors for the incidence of CKD [7].

In addition to hypertension, type $2 \mathrm{DM}$, and metabolic syndrome, the incidence of CKD is also closely correlated with unhealthy lifestyle behaviors such as smoking, heavy alcohol intake, obesity, physical inactivity, and unhealthy diet [8-13]. In our previous cross-sectional and longitudinal studies [14-16], we found that the 
cumulative incidence of CKD significantly decreased as the number of healthy lifestyle behaviors increased. Lifestyle modifications, such as increased daily physical activity and adherence to habitual exercise, are the initial steps for the prevention of CVD [17]. In Japan, the number of patients with ESRD has been continuously increasing according to the increase in the incidence of type 2 DM [1]. The aim of glycemic control is not only to reduce the blood glucose level but also to prevent the development of CKD, ESRD, and CVD. Thus, we believe that the early stage of lifestyle counseling, with a particular focus on the regular performance of moderate exercise in order to improve hyperglycemia, is necessary for preventing the development of CKD, ESRD, and CVD. However, at present, the influence of habitual exercise and glycemic control alone and in combination on the incidence of CKD remains controversial.

We therefore hypothesized that a lack of habitual exercise and poor glycemic control and their combination might predict the incidence of CKD. Clarifying the influence of habitual exercise and glycemic control and their combination on the incidence of CKD may highlight the importance of CKD prevention. This retrospective study evaluated the influence of habitual exercise and glycemic control and their combination on the incidence of CKD during a 6-year follow-up period in middle-aged and older males.

\section{Methods \\ Subjects}

A total of 773 middle-aged and older adults received their periodic health checkup at a health-care center in Fukuoka University in 2008. Figure 1 shows a flow chart of the participants who were included in this study. Among the 612 subjects who provided their informed consent, 178 females were excluded to remove the influence of gender. Subjects with a previous history of CVD, such as angina and myocardial infarction $(n=4)$, stroke $(n=2)$, renal dysfunction (glomerular filtration rate estimated by the Japanese estimated glomerular filtration rate (eGFR) inference formula $<60 \mathrm{ml} / \mathrm{min} / 1.73 \mathrm{~m}^{2}$, proteinuria, or both) [18], and/or dialysis treatment $(n=45)$, were also excluded from the analysis. A total of 303 males (age $=52.2 \pm 6.7$ years, body mass index $(\mathrm{BMI})=23.4 \pm 2.8 \mathrm{~kg} / \mathrm{m}^{2}$, serum creatinine $=0.84 \pm 0.09 \mathrm{mg} / \mathrm{dl}$, and eGFR $=77.0 \pm 10.3 \mathrm{ml} / \mathrm{min} /$ $1.73 \mathrm{~m}^{2}$ ) with no missing information over the previous 6 years were eligible for inclusion in the present study. In this study, subjects taking anti-hypertensive drugs, antihyperlipidemic agents, or hypoglycemic agents were included (anti-hypertensive drug users, $n=43$; antihyperlipidemic agent users, $n=25$; hypoglycemic agent users, $n=7$ ).

All of the subjects gave their informed consent to participate after agreeing with the purpose, methods, and significance of the study. The study conformed to the Declaration

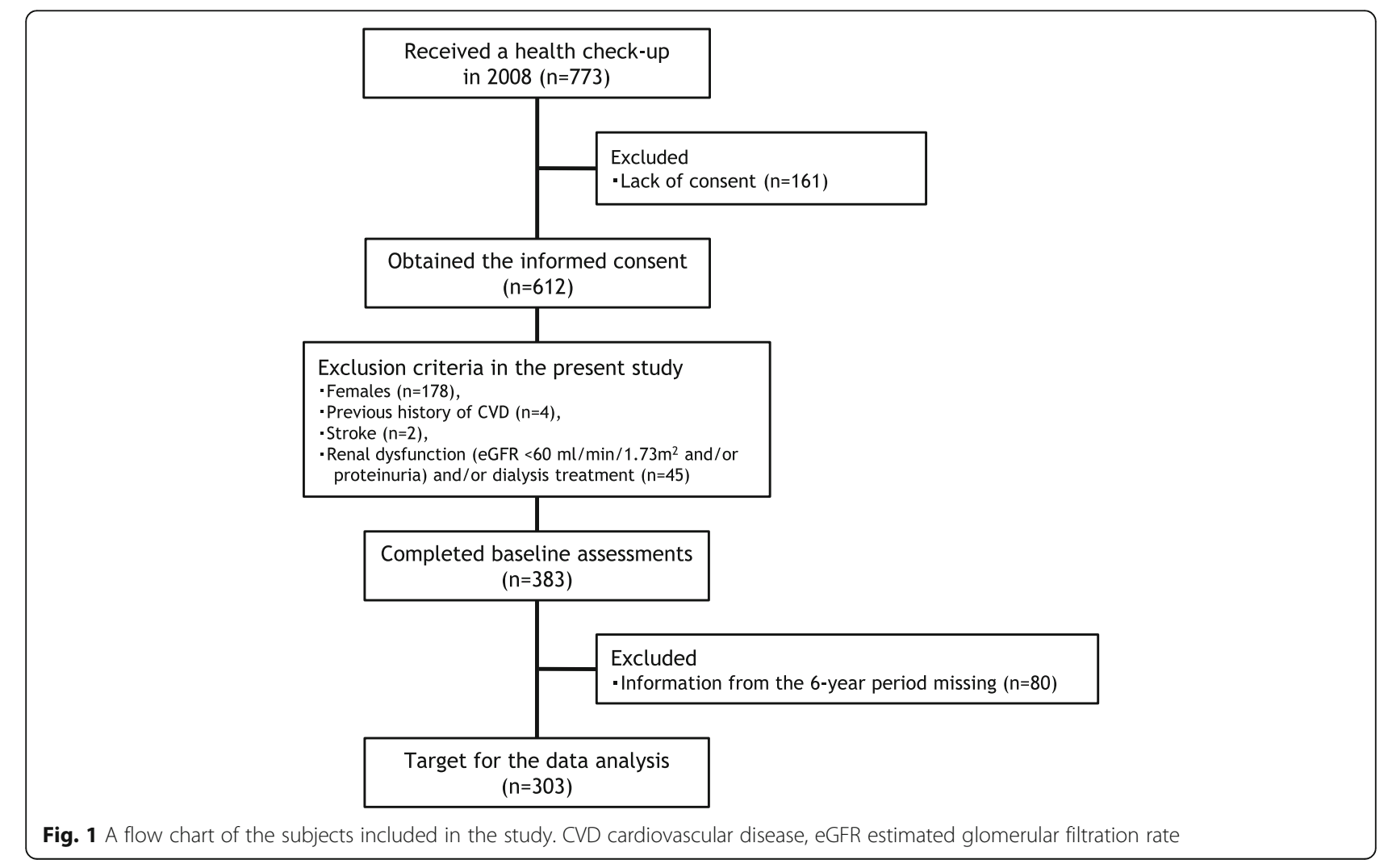


of Helsinki guidelines and was approved by the Ethics Committee of Fukuoka University (No. 11-08-01).

\section{Blood sampling, blood pressure, and anthropometry measurement}

Blood samples were collected early in the morning, after at least $12 \mathrm{~h}$ of fasting, from an antecubital vein by venipuncture. The blood samples were analyzed by Special Reference Laboratories (SRL, Inc., Tokyo, Japan). The serum creatinine, high-density lipoprotein cholesterol (HDL-C), and low-density lipoprotein cholesterol (LDL-C) levels were measured by the direct method. The triglyceride level was measured by the enzyme method. The plasma glucose level was measured by an ultraviolet/hexokinase method, and the hemoglobin $\mathrm{A}_{1} \mathrm{c}\left(\mathrm{HbA}_{1} \mathrm{c}\right)$ level was measured by highperformance liquid chromatography. The $\mathrm{HbA}_{1} \mathrm{c}$ level was presented as the National Glycohemoglobin Standardization Program (NGSP) and International Federation of Clinical Chemistry and Laboratory Medicine (IFCC) values, which was calculated using the conversion equation for $\mathrm{HbA}_{1} \mathrm{c}$ derived from the Japan Diabetes Society (JDS): $\mathrm{HbA}_{1} \mathrm{c}$ (NGSP value; $\%)=1.02 \times \mathrm{JDS}$ value $(\%)+0.25 \%$ [19], and $\mathrm{HbA}_{1} \mathrm{c}$ $($ IFCC value; $\mathrm{mmol} / \mathrm{mol})=10.93 \times \mathrm{NGSP}$ value $(\%)-23.50$ [20]. Hyperglycemia was defined based on the fasting plasma glucose and $\mathrm{HbA}_{1} \mathrm{c}$ levels according to the criteria of the Japan Diabetes Society as follows: fasting glucose $\geq$ $110 \mathrm{mg} / \mathrm{dl}$ and/or $\mathrm{HbA}_{1} \mathrm{c}$ (NGSP value) $\geq 6.5 \%$ (IFCC value $>48 \mathrm{mmol} / \mathrm{mol}$ ) and/or the use of hypoglycemic drugs [21].

The grade of CKD was classified according to the eGFR level and the presence of proteinuria. The eGFR was calculated using the Japanese GFR inference formula, as follows: eGFR $\left(\mathrm{ml} / \mathrm{min} / 1.73 \mathrm{~m}^{2}\right)=194 \times$ serum creatinine $(\mathrm{mg} / \mathrm{dl})^{-1.094} \times$ age (years) $)^{-0.287}$ [22]. The GFR is a more accurate measure of the renal function than the serum creatinine level [23] and identifies patients who have mild renal impairment despite having normal or nearly normal creatinine levels. In addition, the eGFR is a strong predictor of cardiovascular events and is more useful for this purpose than the serum creatinine level [24, 25]. A urinalysis was performed using a dipstick, and the urine test results were classified as $(-)$, $( \pm),(1+),(2+)$, and $(3+)$ [26]. In the present study, CKD was defined according to definition of the Japanese Society of Nephrology as follows: eGFR $<60 \mathrm{ml} / \mathrm{min} /$ $1.73 \mathrm{~m}^{2}$, positive proteinuria (1+ or greater), or both [18]. The breakdown of the CKD grade of the subjects at baseline [18] was as follows: G1 (eGFR $\geq 90 \mathrm{ml} / \mathrm{min} /$ $\left.1.73 \mathrm{~m}^{2}\right), n=29(9.6 \%)$, and G2 (eGFR $60-89 \mathrm{ml} / \mathrm{min} /$ $\left.1.73 \mathrm{~m}^{2}\right), n=274(90.4 \%)$.

Blood pressure was measured in the right arm with the subject sitting in a chair, after at least $5 \mathrm{~min}$ of rest, and was expressed as an average of duplicate measurements. The height and body weight were measured, and the BMI was calculated as the ratio of the body weight $(\mathrm{kg})$ to the height squared $\left(\mathrm{m}^{2}\right)$. The waist circumference was measured at the level of the umbilicus.

\section{The assessment of lifestyle behaviors}

The subjects' lifestyle behaviors with regard to exercise, physical activity, and drinking and smoking habits were selected for based on the standardized self-administered questionnaire of the National Health Promotion Program, which was started in Japan in the fiscal year of 2008 and which aimed at preventing CVD, stroke, and metabolic syndrome $[27,28]$. Our previous studies have shown that the combination of healthy lifestyle behaviors regarding exercise, physical activity, and diet is related to the incidence/prevalence of CKD in middle-aged and older males [14-16]. The subjects' lifestyle behaviors regarding physical activity, exercise, eating style, and drinking and smoking habits were determined based on their responses to the following questionnaire items: habitual moderate exercise, $\geq 30 \mathrm{~min}$ at a time and $\geq 2$ times per week (yes or no); physical activity equal to walking at least $1 \mathrm{~h}$ per day (yes or no); walking speed, compared with people of the same sex and age group (fast or slow); eating speed, compared with others (fast or slow); late night dinner, $\geq 3$ times per week (yes or no); bedtime snacking, $\geq 3$ times per week (yes or no); and skipping breakfast, $\geq 3$ times per week (yes or no). The subjects' drinking and smoking habits were assessed by the following questionnaire items (with "yes" or "no" responses): drinking habit (not drinking everyday) and smoking habit (recently not smoking). In this study, the subjects' exercise habits were determined based on their responses to the following questionnaire items: habitual moderate exercise, $\geq 30 \mathrm{~min}$ at a time and $\geq 2$ times per week (yes or no), physical activity equal to walking at least $1 \mathrm{~h}$ per day (yes or no), or both.

\section{Statistical analyses}

In this study, subjects were followed for 6 years from October 2008 to October 2014. The biochemical analysis, blood pressure and anthropometry measurements, and assessment of lifestyle behaviors were conducted from baseline (2008) to end-point year (2014). The data were expressed as the mean and the standard deviation (SD). The StatView J-5.0 software package (SAS Institute, Cary, NC, USA) was used for all of the statistical analyses. In the present study, the subjects' exercise and drinking and smoking habits were expressed as categorical variables, and the biochemical, blood pressure, and anthropometric indices were shown as continuous variables. As a result, the present study only analyzed data from participants who received their periodic health checkups during the 6-year study period. Inter-group comparisons were performed using the Mann-Whitney $U$ test for continuous variables and the chi-square test for categorical variables. Within-group 
comparisons were determined using the one-way repeated-measures analysis of variance (ANOVA) and Scheffés method. The cumulative incidence of CKD was determined using the Kaplan-Meier survival curves and the log-rank test. A Cox proportional hazards model was used to predict the incidence of CKD using the parameters as categorical variables. This Cox proportional hazards model was adjusted for the following factors: age, BMI, eGFR, the use of anti-hypertensive drugs and anti-hyperlipidemic agents, and smoking and drinking habits at baseline. Probability values of $<0.05$ were considered to indicate statistical significance.

\section{Results}

After 6 years, the incidence of CKD (eGFR $<60 \mathrm{ml} / \mathrm{min} /$ $1.73 \mathrm{~m}^{2}$ and/or proteinuria) was observed in 32 subjects (10.6\%). After 6 years, the CKD grades of the subjects [18] were as follows: G1 (eGFR $\geq 90 \mathrm{ml} / \mathrm{min} / 1.73 \mathrm{~m}^{2}$ ), $n=10$ (3.3\%); G2 (eGFR 60-89 $\mathrm{ml} / \mathrm{min} / 1.73 \mathrm{~m}^{2}$ ), $n=261$ (86.1\%); and G3a (eGFR 45-59 ml/min/ $\left.1.73 \mathrm{~m}^{2}\right), n=32$ (10.6\%; including two with proteinuria). Table 1 shows the baseline characteristics of the subject who did and did not develop CKD. In the CKD group, the serum creatinine level, age, systolic blood pressure, diastolic blood pressure, fasting glucose, $\mathrm{HbA}_{1} \mathrm{c}$ levels, and rate of anti-hypertensive or anti-hyperlipidemic drug use were significantly higher and the eGFR, HDL-C levels, and the percentage of subjects who performed habitual exercise were significantly lower in comparison to the non-CKD group ( $p<0.05$, respectively). There were no significant differences in the other risk factors of the two groups.

Table 2 shows the baseline characteristics of the subject with and without habitual exercise and hyperglycemia. Among subjects who did not perform habitual exercise, systolic blood pressure (SBP), $\mathrm{HbA}_{1} \mathrm{c}$ level, and rate of anti-hyperlipidemic agent use were significantly higher and HDL-C level was lower in comparison to

Table 1 The baseline characteristics in subjects with and without the development of CKD

\begin{tabular}{|c|c|c|c|c|}
\hline & All $(n=303)$ & Developed CKD $(n=32)$ & Did not develop CKD $(n=271)$ & $p$ value \\
\hline eGFR $\left(\mathrm{ml} / \mathrm{min} / 1.73 \mathrm{~m}^{2}\right)$ & $77.0 \pm 10.3$ & $66.8 \pm 5.3$ & $78.2 \pm 10.1$ & $<0.0001$ \\
\hline \multicolumn{5}{|l|}{ Classifications of CKD grade } \\
\hline $\mathrm{G} 1\left(n, \% ; \mathrm{eGFR} \geq 90 \mathrm{ml} / \mathrm{min} / 1.73 \mathrm{~m}^{2}\right)$ & $29(9.6)$ & $0(0)$ & $29(10.7)$ & \multirow[t]{2}{*}{0.052} \\
\hline $\mathrm{G} 2\left(\mathrm{n}, \%\right.$; eGFR $\left.60-89 \mathrm{ml} / \mathrm{min} / 1.73 \mathrm{~m}^{2}\right)$ & $274(90.4)$ & $32(100)$ & $242(89.3)$ & \\
\hline Serum creatinine (mg/dl) & $0.84 \pm 0.09$ & $0.93 \pm 0.06$ & $0.83 \pm 0.09$ & $<0.0001$ \\
\hline Age (years) & $52.2 \pm 6.7$ & $54.6 \pm 6.5$ & $51.9 \pm 6.7$ & 0.030 \\
\hline Body weight (kg) & $67.6 \pm 9.3$ & $67.7 \pm 9.0$ & $67.5 \pm 9.4$ & 0.902 \\
\hline BMI $\left(\mathrm{kg} / \mathrm{m}^{2}\right)$ & $23.4 \pm 2.8$ & $23.3 \pm 2.7$ & $23.4 \pm 2.8$ & 0.921 \\
\hline Waist circumference $(\mathrm{cm})$ & $83.5 \pm 7.6$ & $84.6 \pm 7.2$ & $83.4 \pm 7.6$ & 0.379 \\
\hline SBP $(\mathrm{mmHg})$ & $126.8 \pm 15.4$ & $133.7 \pm 15.2$ & $126.0 \pm 15.2$ & 0.007 \\
\hline $\mathrm{DBP}(\mathrm{mmHg})$ & $83.0 \pm 10.4$ & $86.6 \pm 9.4$ & $82.6 \pm 10.5$ & 0.038 \\
\hline LDL-C (mg/dl) & $118.4 \pm 25.2$ & $119.4 \pm 25.3$ & $118.3 \pm 25.1$ & 0.819 \\
\hline $\mathrm{HDL}-\mathrm{C}(\mathrm{mg} / \mathrm{dl})$ & $58.2 \pm 13.3$ & $53.7 \pm 11.0$ & $58.7 \pm 13.5$ & 0.043 \\
\hline Triglyceride (mg/dl) & $115.0 \pm 69.9$ & $132.0 \pm 124.0$ & $113.0 \pm 60.4$ & 0.145 \\
\hline Fasting glucose (mg/dl) & $100.5 \pm 18.1$ & $107.1 \pm 30.1$ & $99.7 \pm 16.1$ & 0.030 \\
\hline $\mathrm{HbA}_{1} \mathrm{C}$ (NGSP values; \%) & $5.6 \pm 0.7$ & $5.9 \pm 0.9$ & $5.6 \pm 0.7$ & 0.031 \\
\hline $\mathrm{HbA}_{1} \mathrm{C}$ (IFCC values; \%) & $38.0 \pm 7.7$ & $40.7 \pm 9.6$ & $37.7 \pm 7.4$ & 0.031 \\
\hline Smoking habit (yes/no; $n, \%)$ & $63(20.8) / 240(79.2)$ & $5(15.6) / 27(84.4)$ & $58(21.4) / 213(78.6)$ & 0.446 \\
\hline Drinking habit (yes/no; $n, \%)$ & $232(76.6) / 71(23.4)$ & $21(65.6) / 11(34.4)$ & $211(77.9) / 60(22.1)$ & 0.122 \\
\hline Anti-hypertensive drugs (yes/no; $n, \%$ ) & $43(14.2) / 260(85.8)$ & $9(28.1) / 23(71.9)$ & $34(12.5) / 237(87.5)$ & 0.017 \\
\hline Anti-hyperlipidemic agents (yes/no; $n, \%$ ) & $25(8.3) / 278(91.7)$ & $7(21.9) / 25(78.1)$ & $18(6.6) / 253(93.4)$ & 0.003 \\
\hline Hypoglycemic drugs (yes/no; $n, \%$ ) & $7(2.3) / 296(97.7)$ & $2(6.3) / 30(93.7)$ & $5(1.8) / 266(98.2)$ & 0.117 \\
\hline Exercise habit (yes/no; $n, \%$ ) & $148(48.8) / 155(51.2)$ & $10(31.3) / 22(68.7)$ & $138(50.9) / 133(49.1)$ & 0.035 \\
\hline
\end{tabular}

The data are expressed as the mean \pm standard deviation and the number of subjects. The CKD grades were defined according to the definitions of the Japanese Society of Nephrology [18]. The exercise habit was determined based on the subjects' responses to the following questionnaire items: habitual moderate exercise $\geq 30 \mathrm{~min}$ at a time and $\geq 2$ times per week and/or physical activity equal to walking at least $1 \mathrm{~h}$ per day

$C K D$ chronic kidney disease, eGFR estimated glomerular filtration rate, $B M I$ body mass index, SBP systolic blood pressure, $D B P$ diastolic blood pressure, $L D L-C$ low-

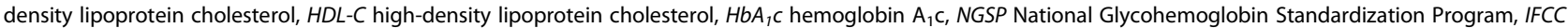
International Federation of Clinical Chemistry and Laboratory Medicine 
Table 2 The baseline characteristics in subjects with and without habitual exercise and hyperglycemia

\begin{tabular}{|c|c|c|c|c|c|c|}
\hline & \multicolumn{2}{|l|}{ Habitual exercise } & \multirow[t]{2}{*}{$p$ value } & \multicolumn{2}{|c|}{ Presence/absence of hyperglycemia } & \multirow[t]{2}{*}{$p$ value } \\
\hline & Yes $(n=148)$ & No $(n=155)$ & & NGT $(n=255)$ & Hyperglycemia $(n=48)$ & \\
\hline eGFR $\left(\mathrm{ml} / \mathrm{min} / 1.73 \mathrm{~m}^{2}\right)$ & $77.3 \pm 10.5$ & $76.7 \pm 10.2$ & 0.583 & $76.0 \pm 9.5$ & $77.2 \pm 10.5$ & 0.495 \\
\hline \multicolumn{7}{|l|}{ Classifications of CKD grade } \\
\hline $\mathrm{G} 1\left(n, \% ; \mathrm{eGFR} \geq 90 \mathrm{ml} / \mathrm{min} / 1.73 \mathrm{~m}^{2}\right)$ & $12(8.1)$ & $17(11.0)$ & 0.396 & $26(10.2)$ & $3(6.3)$ & 0.348 \\
\hline $\mathrm{G} 2\left(n, \% ;\right.$ eGFR $\left.60-89 \mathrm{ml} / \mathrm{min} / 1.73 \mathrm{~m}^{2}\right)$ & $136(91.9)$ & $138(89.0)$ & & $229(89.8)$ & $45(93.7)$ & \\
\hline Serum creatinine (mg/dl) & $0.83 \pm 0.10$ & $0.85 \pm 0.09$ & 0.225 & $0.83 \pm 0.09$ & $0.84 \pm 0.10$ & 0.583 \\
\hline Age (years) & $52.1 \pm 6.5$ & $52.3 \pm 6.8$ & 0.887 & $51.5 \pm 6.7$ & $55.6 \pm 5.9$ & $<0.0001$ \\
\hline Body weight (kg) & $66.8 \pm 9.9$ & $68.4 \pm 8.8$ & 0.176 & $67.1 \pm 9.1$ & $69.5 \pm 10.0$ & 0.099 \\
\hline $\mathrm{BMI}\left(\mathrm{kg} / \mathrm{m}^{2}\right)$ & $23.1 \pm 2.6$ & $23.7 \pm 2.8$ & 0.094 & $23.3 \pm 2.2$ & $24.2 \pm 2.6$ & 0.137 \\
\hline Waist circumference (cm) & $81.1 \pm 8.0$ & $85.4 \pm 7.1$ & 0.086 & $82.3 \pm 7.5$ & $85.6 \pm 7.9$ & 0.166 \\
\hline $\mathrm{SBP}(\mathrm{mmHg})$ & $125.1 \pm 15.6$ & $129.6 \pm 14.7$ & 0.041 & $125.3 \pm 14.6$ & $134.2 \pm 17.3$ & 0.002 \\
\hline $\mathrm{DBP}(\mathrm{mmHg})$ & $81.6 \pm 10.4$ & $83.8 \pm 10.4$ & 0.753 & $82.1 \pm 10.2$ & $85.9 \pm 11.2$ & 0.048 \\
\hline LDL-C (mg/dl) & $117.0 \pm 26.3$ & $119.7 \pm 24.1$ & 0.346 & $118.9 \pm 25.3$ & $116.0 \pm 24.5$ & 0.456 \\
\hline $\mathrm{HDL}-\mathrm{C}(\mathrm{mg} / \mathrm{dl})$ & $60.3 \pm 13.2$ & $56.1 \pm 13.1$ & 0.005 & $59.7 \pm 13.1$ & $54.3 \pm 14.3$ & 0.009 \\
\hline Triglyceride (mg/dl) & $111.8 \pm 69.1$ & $117.9 \pm 70.6$ & 0.452 & $110.4 \pm 67.9$ & $138.2 \pm 75.3$ & 0.010 \\
\hline Fasting glucose (mg/dl) & $97.8 \pm 14.9$ & $104.2 \pm 20.8$ & 0.146 & $95.0 \pm 7.7$ & $128.3 \pm 27.9$ & $<0.0001$ \\
\hline $\mathrm{HbA}_{1} \mathrm{c}$ (NGSP values; \%) & $5.5 \pm 0.6$ & $5.8 \pm 0.8$ & 0.036 & $5.4 \pm 0.4$ & $6.4 \pm 1.3$ & $<0.0001$ \\
\hline $\mathrm{HbA}_{1} \mathrm{C}$ (IFCC values; \%) & $35.5 \pm 6.8$ & $40.4 \pm 8.4$ & 0.031 & $36.3 \pm 3.9$ & $46.6 \pm 13.9$ & $<0.0001$ \\
\hline Smoking habit (yes/no; $n, \%$ ) & $30(20.3) / 118(79.7)$ & $33(21.3) / 122(78.7)$ & 0.827 & $56(22.0) / 199(78.0)$ & $7(14.6) / 41(85.4)$ & 0.195 \\
\hline Drinking habit (yes/no; $n, \%)$ & $119(80.4) / 29(19.6)$ & $113(72.9) / 42(27.1)$ & 0.123 & $192(75.3) / 63(24.7)$ & $40(83.3) / 8(16.7)$ & 0.531 \\
\hline Anti-hypertensive drugs (yes/no; $n, \%$ ) & $19(12.8) / 129(87.2)$ & $24(15.5) / 131(84.5)$ & 0.509 & $29(11.4) / 226(88.6)$ & $14(29.2) / 34(70.8)$ & 0.002 \\
\hline Anti-hyperlipidemic agents (yes/no; $n, \%$ ) & $17(11.5) / 131(88.5)$ & $8(5.2) / 147(94.8)$ & 0.046 & $19(7.5) / 236(92.5)$ & $6(12.5) / 42(87.5)$ & 0.292 \\
\hline Hypoglycemic drugs (yes/no; $n, \%$ ) & $2(1.4) / 146(98.6)$ & $5(3.2) / 150(96.8)$ & 0.278 & $0(0) / 255(100)$ & $7(14.6) / 41(85.4)$ & $<0.0001$ \\
\hline
\end{tabular}

The data are expressed as the mean \pm standard deviation and the number of subjects

The abbreviations are the same as those in Table 1

subjects who performed habitual exercise $(p<0.05$, respectively). Among hyperglycemic subjects, age, SBP, diastolic blood pressure (DBP), triglyceride, fasting glucose, $\mathrm{HbA}_{1} \mathrm{c}$ levels, and rate of anti-hypertensive or hypoglycemic drug use were significantly higher and HDL-C level was lower in comparison to the normal glucose tolerance (NGT) subjects ( $p<0.05$, respectively). Figures 2 and 3 show the cumulative incidence of CKD over the 6-year follow-up period in subjects with and without habitual exercise and hyperglycemia. When the subjects were categorized according to the performance/ non-performance of habitual exercise, the Kaplan-Meier survival curve showed that the cumulative incidence of CKD was significantly higher among subjects who did not perform habitual exercise (log-rank test: $p=0.029$, Fig. 2a). When the subjects were categorized according to their glycemic control, the cumulative incidence of CKD among hyperglycemic subjects was significantly higher than that among NGT subjects (log-rank test: $p=0.003$, Fig. 2b).

The subjects were also divided into four categories based on the combination of the performance/non- performance of habitual exercise and the presence/absence of hyperglycemia. Table 3 shows the baseline characteristics of the subject according to the combination of habitual exercise (performance/non-performance) and hyperglycemia (presence/absence). Age, SBP, and rate of anti-hypertensive drug use were significantly higher, and HDL-C level was lower in the hyperglycemic subjects who did not perform habitual exercise than in the NGT subjects who performed habitual exercise $(p<0.05$, respectively). Fasting glucose, $\mathrm{HbA}_{1} \mathrm{c}$ levels, and rate of hypoglycemic drug use were significantly higher in the hyperglycemic subjects who performed and did not perform habitual exercise than in the NGT subjects who performed and did not perform habitual exercise $(p<0.05$, respectively). There were no significant differences in the other coronary risk factors among the four groups. The cumulative incidence of CKD in hyperglycemic subjects who did not perform habitual exercise was significantly higher than that among NGT subjects who did not perform habitual exercise, hyperglycemic subjects who performed habitual exercise, and NGT subjects who performed habitual exercise (log-rank test: 
(a)

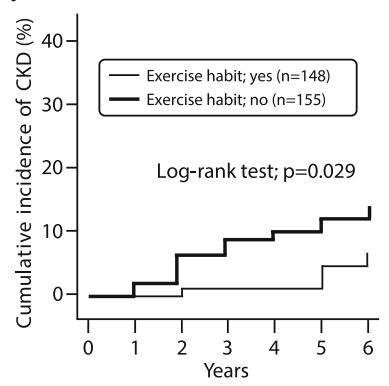

(b)

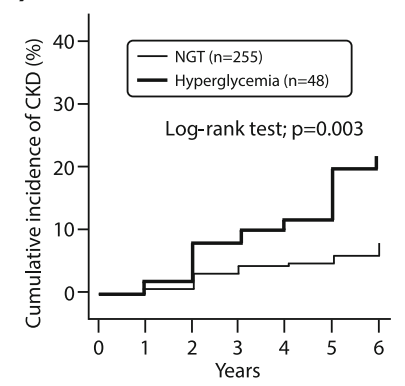

Fig. 2 The cumulative incidence of CKD after a 6-year follow-up period in subjects according to the performance/non-performance of habitual exercise (a) and the presence/absence of hyperglycemia (b). NGT normal glucose tolerance

$p=0.004$, Fig. 3). In a univariate analysis, the nonperformance of habitual exercise was significantly associated with the incidence of CKD in the subjects with a NGT $(\mathrm{HR}=2.77,95 \% \mathrm{CI}=1.08-7.08, p=0.033)$ and in the hyperglycemic subjects $(\mathrm{HR}=6.77,95 \% \mathrm{CI}=2.18$ 18.02, $p=0.001$ ). Furthermore, after adjusting for age, BMI, eGFR, the use of anti-hypertensive and antihyperlipidemic drugs, and smoking and drinking habits at baseline, the non-performance of habitual exercise remained associated with the incidence of CKD in the subjects with NGT $(\mathrm{HR}=2.82,95 \% \mathrm{CI}=1.07-7.36$, $p=0.034)$ and the hyperglycemic subjects $(\mathrm{HR}=5.89$, $95 \% \mathrm{CI}=1.87-16.63, p=0.003$, Table 4 ).

\section{Discussion}

The major findings of our study were that the nonperformance of habitual exercise and hyperglycemia were significantly associated with the incidence of CKD. In addition, the relative risk for the incidence of CKD among hyperglycemic subjects who did not perform habitual exercise was significantly higher than that among NGT subjects who performed habitual exercise. The results of the present study suggest that a lack of habitual exercise and poor glycemic control alone and in combination are independent risk factors for the incidence of CKD.

Adherence to habitual exercise is well known to be related to a decreased incidence of cardiovascular morbidity

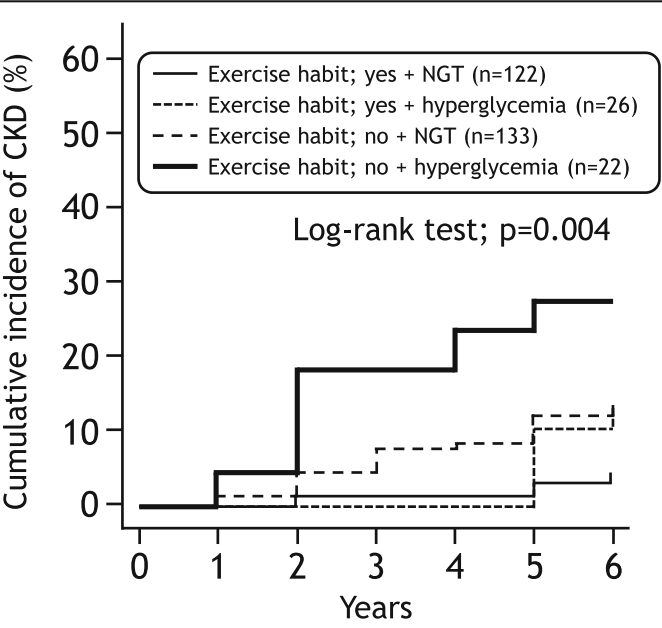

\begin{tabular}{lllllllc} 
Number of CKD subjects & & & & & & & Total \\
\hline Exercise habit; yes + NGT & 0 & 2 & 0 & 0 & 2 & 2 & 6 \\
Exercise habit; yes + hyperglycemia & 0 & 0 & 0 & 0 & 3 & 1 & 4 \\
Exercise habit; no + NGT & 2 & 4 & 4 & 1 & 2 & 3 & 16 \\
Exercise habit; no + hyperglycemia & 1 & 3 & 0 & 1 & 1 & 0 & 6 \\
\hline Total & 3 & 9 & 4 & 2 & 8 & 6 & 32 \\
\hline
\end{tabular}

Fig. 3 The cumulative incidence of CKD after 6 years of follow-up according to the combination of habitual exercise (performance/non-performance) and hyperglycemia (presence/absence). NGT normal glucose tolerance 
Table 3 The baseline characteristics in subjects according to the combination of habitual exercise (performance/non-performance) and hyperglycemia (presence/absence)

\begin{tabular}{|c|c|c|c|c|c|}
\hline & \multicolumn{2}{|c|}{ Performance of habitual exercise } & \multicolumn{2}{|c|}{ Non-performance of habitual exercise } & \multirow{2}{*}{$\begin{array}{l}p \text { for } \\
\text { ANOVA }\end{array}$} \\
\hline & $\operatorname{NGT}(n=122)$ & Hyperglycemia $(n=26)$ & $\operatorname{NGT}(n=133)$ & Hyperglycemia $(n=22)$ & \\
\hline eGFR $\left(\mathrm{ml} / \mathrm{min} / 1.73 \mathrm{~m}^{2}\right)$ & $77.2 \pm 10.7$ & $78.6 \pm 10.8$ & $76.9 \pm 10.4$ & $73.9 \pm 7.2$ & 0.443 \\
\hline \multicolumn{6}{|l|}{ Classifications of CKD grade } \\
\hline G1 $\left(n, \% ;\right.$ eGFR $\left.\geq 90 \mathrm{ml} / \mathrm{min} / 1.73 \mathrm{~m}^{2}\right)$ & $10(8.2)$ & $3(11.5)$ & $16(12.0)$ & $0(0)$ & 0.247 \\
\hline G2 (n, \%; eGFR 60-89 ml/min/1.73 m²) & $112(91.8)$ & $23(88.5)$ & $117(88.0)$ & $22(100)$ & \\
\hline Serum creatinine (mg/dl) & $0.84 \pm 0.10$ & $0.81 \pm 0.10$ & $0.85 \pm 0.09$ & $0.85 \pm 0.08$ & 0.363 \\
\hline Age (years) & $50.5 \pm 6.8$ & $54.8 \pm 6.4$ & $52.6 \pm 6.5$ & $56.0 \pm 5.3^{a}$ & 0.002 \\
\hline Body weight (kg) & $67.4 \pm 9.8$ & $69.3 \pm 10.4$ & $67.0 \pm 8.5$ & $69.4 \pm 10.1$ & 0.515 \\
\hline BMI $\left(\mathrm{kg} / \mathrm{m}^{2}\right)$ & $23.0 \pm 2.4$ & $23.7 \pm 2.2$ & $23.3 \pm 2.9$ & $23.4 \pm 2.4$ & 0.937 \\
\hline Waist circumference (cm) & $83.2 \pm 8.2$ & $84.3 \pm 7.1$ & $83.3 \pm 6.8$ & $85.5 \pm 9.1$ & 0.566 \\
\hline $\mathrm{SBP}(\mathrm{mmHg})$ & $123.6 \pm 15.1$ & $132.7 \pm 13.0$ & $127.4 \pm 14.1$ & $134.5 \pm 20.5^{a}$ & 0.001 \\
\hline $\mathrm{DBP}(\mathrm{mmHg})$ & $82.3 \pm 10.2$ & $85.6 \pm 12.4$ & $82.8 \pm 10.2$ & $85.4 \pm 10.5$ & 0.341 \\
\hline LDL-C (mg/dl) & $117.3 \pm 26.2$ & $117.7 \pm 25.3$ & $120.7 \pm 24.3$ & $114.6 \pm 24.0$ & 0.486 \\
\hline $\mathrm{HDL}-\mathrm{C}(\mathrm{mg} / \mathrm{dl})$ & $60.7 \pm 12.8$ & $56.8 \pm 13.0$ & $55.8 \pm 14.8$ & $54.3 \pm 14.3^{\mathrm{a}}$ & 0.032 \\
\hline Triglyceride (mg/dl) & $109.2 \pm 67.7$ & $111.1 \pm 68.0$ & $139.4 \pm 76.3$ & $141.8 \pm 77.4$ & 0.052 \\
\hline Fasting glucose (mg/dl) & $94.1 \pm 9.8$ & $126.5 \pm 26.4^{\mathrm{a}, \mathrm{b}}$ & $96.6 \pm 7.4$ & $129.3 \pm 28.6^{\mathrm{a}, \mathrm{b}}$ & $<0.0001$ \\
\hline $\mathrm{HbA}_{1} \mathrm{C}$ (NGSP values; \%) & $5.5 \pm 0.4$ & $6.3 \pm 1.3^{a, b}$ & $5.5 \pm 0.4$ & $6.4 \pm 0.9^{\mathrm{a}, \mathrm{b}}$ & $<0.0001$ \\
\hline $\mathrm{HbA}_{1} \mathrm{C}$ (IFCC values; \%) & $36.2 \pm 3.8$ & $46.3 \pm 14.8^{\mathrm{a}, \mathrm{b}}$ & $36.6 \pm 4.4$ & $46.8 \pm 10.2^{a, b}$ & $<0.0001$ \\
\hline Smoking habit (yes/no; $n, \%$ ) & $27(22.1) / 95(77.9)$ & $3(11.5) / 23(88.5)$ & $29(21.8) / 104(78.2)$ & $4(18.2) / 18(81.8)$ & 0.630 \\
\hline Drinking habit (yes/no; $n, \%)$ & $100(82.0) / 22(18.0)$ & $19(73.1) / 7(26.9)$ & $96(72.2) / 37(27.8)$ & $17(77.3) / 5(22.7)$ & 0.102 \\
\hline Anti-hypertensive drugs (yes/no; $n, \%$ ) & $16(13.1) / 106(86.9)$ & $3(11.5) / 23(88.5)$ & $15(11.3) / 118(88.7)$ & $9(40.9) / 13(59.1)$ & 0.003 \\
\hline Anti-hyperlipidemic agents (yes/no; $n, \%$ ) & $14(11.5) / 108(88.5)$ & $3(11.5) / 23(88.5)$ & $5(3.8) / 128(96.2)$ & $3(13.6) / 19(86.4)$ & 0.127 \\
\hline Hypoglycemic drugs (yes/no; $n, \%$ ) & $0(0) / 122(100)$ & $2(7.7) / 24(92.3)$ & $0(0) / 133(100)$ & $5(22.7) / 17(77.3)$ & $<0.0001$ \\
\hline
\end{tabular}

The data are expressed as the mean \pm standard deviation and the number of subjects

The abbreviations are the same as those in Table 1

${ }^{a} p<0.05$, compared to the NGT subjects who performed habitual exercise

${ }^{b} p<0.05$, compared to the NGT subjects who did not perform habitual exercise

and mortality [29-32]. Additionally, it is also well known that poor glycemic control is an important independent risk factor for the development of CVD [33]. We hypothesize that similar mechanisms underlie the relationship between the non-performance of habitual exercise and poor glycemic control and their combination with the incidence of CKD and that adherence to habitual exercise and good glycemic control and their combination plays a pivotal role in the prevention of cardiovascular events. Dunkler et al. [34] investigated the effects of modifiable lifestyle factors on the incidence of CKD and mortality in individuals with type $2 \mathrm{DM}$ and showed that there was a significant increase in the incidence of CKD development and in the mortality rate as the lifestyle scores decreased. Ricardo et al. [35] evaluated the influence of four health lifestyle factors (regular physical activity, maintaining a reasonable body weight, not smoking, and enjoying a healthy eating style) on the incidence of CKD progression, cardiovascular events, and all-cause mortality and found that the incidence of CKD and atherosclerotic events and the rate of all-cause mortality were significantly reduced as the healthy lifestyle score increased. A previous meta-analysis [11] reported that a lack of habitual exercise and decreased physical activity influenced the incidence of CKD. Those authors showed that the incidence of CKD, cardiovascular events, and all-cause mortality were significantly reduced as the healthy lifestyle behaviors including exercise and physical activity increased. Our recent cross-sectional and longitudinal studies [14-16] also found that an increase in healthy lifestyle behaviors, especially those related to a lack of habitual exercise, may be predictive factors for the incidence of CKD. Furthermore, we also demonstrated that hypertension and hyperglycemia and their combination may be independent risk factors for the incidence of CKD [7]. At present, the number of patients with ESRD in Japan is continuously increasing according to the increase in the incidence of type 2 DM [1]. Thus, our current findings 
Table 4 The influence of the combination of an exercise habit and the glycemic control on the incidence of CKD

\begin{tabular}{|c|c|c|c|c|c|c|c|}
\hline & \multirow[t]{2}{*}{ Total } & \multirow{2}{*}{$\begin{array}{l}\text { Developed CKD } \\
(n, \text { per } 10,000 \text { person-years })\end{array}$} & \multirow{2}{*}{$\begin{array}{l}\text { Developed proteinuria } \\
\text { (n, per 10,000 person-years) }\end{array}$} & \multicolumn{2}{|l|}{ Univariate model } & \multicolumn{2}{|c|}{ Multivariable model } \\
\hline & & & & $\begin{array}{l}\text { Hazard ratio } \\
(95 \% \mathrm{Cl})\end{array}$ & $p$ value & $\begin{array}{l}\text { Hazard ratio } \\
(95 \% \mathrm{Cl})\end{array}$ & $p$ value \\
\hline \multicolumn{8}{|c|}{ Combined with exercise habit and glycemic control states } \\
\hline Exercise habit; yes + NGT & 122 & $6(82.0)$ & 0 & 1.00 (Ref.) & - & 1.00 (Ref.) & - \\
\hline $\begin{array}{l}\text { Exercise habit; } \\
\text { yes + hyperglycemia }\end{array}$ & 26 & $4(256.4)$ & 0 & $3.29(0.93-9.66)$ & 0.065 & $2.50(0.69-9.14)$ & 0.164 \\
\hline Exercise habit; no + NGT & 133 & $16(200.5)$ & $1(12.5)$ & $2.77(1.08-7.08)$ & 0.033 & $2.82(1.07-7.36)$ & 0.034 \\
\hline $\begin{array}{l}\text { Exercise habit; } \\
\text { no + hyperglycemia }\end{array}$ & 22 & $6(454.5)$ & $1(75.8)$ & $6.77(2.18-18.02)$ & 0.001 & $5.89(1.87-16.63)$ & 0.003 \\
\hline
\end{tabular}

support the possibility that adherence to habitual exercise and good glycemic control and their combination are important for preventing the development of CKD, ESRD, and CVD, and we consider that the early stage of lifestyle counseling, with a particular focus on the importance of regularly performing moderate exercise to improve hyperglycemia, is necessary in order to prevent the development of CKD, ESRD, and CVD.

In the present study, the NGT subjects who did not perform habitual exercise, but not hyperglycemic subjects who performed habitual exercise, were significantly associated with the incidence of CKD. However, at present, the influence of habitual exercise and glycemic control states alone and in combination on the incidence of CKD has not yet been investigated. Nagasawa et al. [36] investigated the association between exercise and the prevalence of proteinuria and kidney dysfunction and the attenuation by obesity and demonstrated habitual exercise may ameliorate the prevalence of proteinuria and kidney dysfunction and a high BMI may attenuate this amelioration in male subjects. On the other hand, Manson et al. [37] examined that the relationships between physical activity level and cardiovascular events and found that daily walking, especially vigorous exercise, was associated with a lower risk of cardiovascular events independent of age and BMI. Lee et al. [38] reported the combined associations of changes in cardiorespiratory fitness and the BMI with all-cause and cardiovascular mortality. Those authors showed that maintaining or improving fitness is associated with a lower risk of all-cause and cardiovascular mortality. Thus, at present, the non-performance of habitual exercise, decreased physical activity, and cardiorespiratory fitness itself are thought to be related to the development of cardiovascular morbidity and mortality independent of aging and obesity. According to these findings, a lack of habitual exercise may be a risk factor for detecting the development of CKD, ESRD, and CVD, independent of glycemic control, at least in the population of the present study because the NGT subjects who did not perform habitual exercise, but not hyperglycemic subjects who performed habitual exercise, were significantly correlated with the incidence of CKD.

\section{Study limitations and clinical implications}

There are several limitations associated with this study. First, the limited study population resulted in a small number of male subjects, who were predominantly middle-aged and older, and those who did not have any health complications. Thus, there was a potential selection bias in this study, as our limited study population may have included more CKD subjects with a slowly declining renal function than CKD subjects with rapid deterioration. As such, it remains unclear whether or not our findings are generalizable to females, patients with ESRD, or individuals with other complications. Second, although this study was performed within the constraints of the health checkup, it was not possible to clarify the causality of the incidence of CKD with a lack of habitual exercise and poor glycemic control. Third, the indices of glucose tolerance in the present study were evaluated based on the fasting glucose and $\mathrm{HbA}_{1} \mathrm{c}$ levels. An impaired glucose tolerance, as measured with an oral glucose tolerance test, was associated with an increased risk of CVD in comparison to an impaired fasting glucose level [33], which could not be evaluated in our subjects. Finally, we calculated the eGFR using the Japanese GFR inference formula [22] and used proteinuria as an index of the renal function. Unfortunately, in the present study, the causality of proteinuria with the lack of habitual exercise and poor glycemic control could not be clarified because of the small number of subjects with proteinuria. To fully clarify the influence of the non-performance of habitual exercise and hyperglycemia and the combination thereof on the renal function, other indices of the renal function, such as urinary protein excretion, microalbuminuria, or cystatin $C$, should be simultaneously assessed. However, we were unable to measure any additional markers of the renal 
function because this study was performed within the constraints of the health checkup.

However, despite these limitations, the present study is the first to elucidate the joint impact of habitual exercise and glycemic control on the incidence of CKD over a long follow-up period. We believe that our results support the notion that habitual exercise and good glycemic control and their combination can prevent the incidence of CKD. In our recent studies, we observed that the combination of healthy lifestyle behaviors with regard to exercise, physical activity, and diet was related to the incidence/prevalence of CKD in middle-aged and older males [14-16]. Furthermore, we found that hypertension and hyperglycemia and their combination may be associated with the incidence of CKD [7]. Thus, the results of the present study show that the non-performance of habitual exercise, hyperglycemia, and the combination of these factors are related to the incidence of CKD. This may support the hypothesis that the non-performance of exercise and poor glycemic control lead to an increase in the incidence of CVD and the development of ESRD. Given our results, we believe that providing lifestyle counseling at an early stage, with a particular focus on the role of regular moderate exercise in improving hyperglycemia, is necessary to prevent the incidence of CKD, ESRD, and CVD. Further investigations in larger study populations, including subjects with other complications, are needed to more precisely clarify the mechanisms, clinical implications, and associations of habitual exercise, glycemic control, and their combination with the incidence of CKD following long-term intervention.

\section{Conclusions}

This retrospective study examined the influence of the joint impact of habitual exercise and glycemic control on the incidence of CKD in middle-aged and older males over a 6-year follow-up period. We demonstrated that the cumulative incidence of CKD among the NGT subjects who did not perform habitual exercise and hyperglycemic subjects who did not perform habitual exercise was significantly higher than in NGT subjects who performed habitual exercise. These results suggest that adherence to habitual exercise and the maintenance of good glycemic control and their combination were associated with the incidence of CKD.

\footnotetext{
Abbreviations

ANOVA: Analysis of variance; BMI: Body mass index; $\mathrm{Cl}$ : Confidence of interval; CKD: Chronic kidney disease; CVD: Cardiovascular disease; DBP: Diastolic blood pressure; DM: Diabetes mellitus; eGFR: Estimated glomerular filtration rate; ESRD: End-stage renal disease; $\mathrm{HbA}_{1} \mathrm{c}$ : Hemoglobin $A_{1} C_{;}$HDL-C: High-density lipoprotein cholesterol; HR: Hazard ratio; IFCC: International Federation of Clinical Chemistry and Laboratory Medicine; LDL-C: Low-density lipoprotein cholesterol; NGSP: National glycohemoglobin standardization program; NGT: Normal glucose tolerance; SBP: Systolic blood pressure
}

\section{Acknowledgements}

We would like to thank Drs. Masaki Munekiyo, Kazunori Mine, and Tatsuhiko Kawarabayashi and the members of the Laboratory of Exercise Physiology and Health Care Center of Fukuoka University for their assistance with the data evaluation. We are grateful to the participants of this study.

\section{Funding}

This work was performed with the supports of Grants-in-Aid from the Ministry of Education, Science, Sports and Culture of Japan (No.

15H03082) and the Fukuoka University Institute for Physical Activity.

\section{Availability of data and materials}

All data generated or analyzed during this study are included in this published article.

\section{Authors' contributions}

RM conceived and designed the study, contributed to conducting the literature survey, performing the statistical analyses, interpreting the data, and preparing the manuscript. TM, SK, ST, AK, and HT contributed to the support analysis of the data. NM was involved in obtaining and surveying the data. YH participated in the design of the study and supervised and provided commentaries to the manuscript text. All authors read and approved the final manuscript.

\section{Ethics approval and consent to participate}

All of the subjects gave their informed consent to participate after agreeing with the purpose, methods, and significance of the study. The study conformed to the Declaration of Helsinki guidelines and was approved by the Ethics Committee of Fukuoka University (No. 11-08-01).

\section{Consent for publication}

Not applicable.

\section{Competing interests}

The authors declare that they have no competing interests.

\section{Publisher's Note}

Springer Nature remains neutral with regard to jurisdictional claims in published maps and institutional affiliations.

\section{Author details}

'Department of Health Development, Institute of Industrial Ecological Sciences, University of Occupational and Environmental Health, Kitakyushu, Japan. ${ }^{2}$ Fukuoka University Institute for Physical Activity, Fukuoka, Japan. ${ }^{3}$ Department of Rehabilitation, Fukuoka University Hospital, Fukuoka, Japan. ${ }^{4}$ Laboratory of Exercise Physiology, Faculty of Health and Sports Science, Fukuoka University, Fukuoka, Japan. ${ }^{5}$ Fukuoka University Health Care Center, Fukuoka, Japan. ${ }^{6}$ Department of Cardiology, Fukuoka University School of Medicine, Fukuoka, Japan.

Received: 20 August 2017 Accepted: 26 October 2017

Published online: 06 November 2017

References

1. The Japanese Society for Dialysis Therapy. Current status of dialysis therapy in Japan. http://docs.jsdt.or.jp/overview/pdf2016/p003.pdf. (Accessed 18 Jan 2017). (in Japanese).

2. Go AS, Chertow GM, Fan D, McCulloch CE, Hsu CY. Chronic kidney disease and the risks of death, cardiovascular events, and hospitalization. N Engl J Med. 2004:351:1296-305.

3. Keith DS, Nichols GA, Gullion CM, Brown JB, Smith DH. Longitudinal follow-up and outcomes among a population with chronic kidney disease in a large managed care organization. Arch Intern Med. 2004;164:659-63.

4. Imai E, Horio M, Iseki K, Yamagata K, Watanabe T, Hara S, Ura N, Kiyohara Y, Hirakata H, Moriyama T, Ando Y, Nitta K, Inaguma D, Narita I, Iso H, Wakai K, Yasuda Y, Tsukamoto Y, Ito S, Makino H, Hishida A, Matsuo S. Prevalence of chronic kidney disease (CKD) in the Japanese general population predicted by the NDRD equation modified by a Japanese coefficient. Clin Exp Nephrol. 2007;11:156-63. 
5. Bakris GL, Williams M, Dworkin L, Elliott WJ, Epstein M, Toto R, Tuttle K, Douglas J, Hsueh W, Sowers J. Preserving renal function in adults with hypertension and diabetes: a consensus approach. National Kidney Foundation Hypertension and Diabetes Executive Committees Working Group. Am J Kidney Dis. 2000;36:646-61.

6. Ninomiya T, Kiyohara Y, Kubo M, Yonemoto K, Tnizaki Y, Doi Y, Hirakata H, lida M. Metabolic syndrome and CKD in a general Japanese population: the Hisayama Study. Am J Kidney Dis. 2006;48:383-91.

7. Michishita R, Matsuda T, Kawakami S, Tanaka S, Kiyonaga A, Tanaka H, Morito N, Higaki Y. Hypertension and hyperglycemia and the combination thereof enhances the incidence of chronic kidney disease (CKD) in middleaged and older males. Clin Exp Hypertens. [Epub ahead of print]

8. Nagasawa Y, Yamamoto R, Rakugi H, Isaka Y. Cigarette smoking and chronic kidney diseases. Hypertens Res. 2012;35:261-5.

9. White SL, Polkinghorne KR, Cass A, Shaw JE, Atkins RC, Chadban SJ. Alcohol consumption and 5-year onset of chronic kidney disease: the AusDiab Study. Nephrol Dial Transplant. 2009;24:2464-72.

10. Iseki K, Ikemiya Y, Kinjo K, Inoue T, Iseki C, Takishita S. Body mass index and the risk of development of end-stage renal disease in a screened cohort. Kidney Int. 2004;65:1870-6.

11. Heiwe $\mathrm{S}$, Jacobson SH. Exercise training in adults with CKD: a systematic review and meta-analysis. Am J Kidney Dis. 2014;64:383-93.

12. Gutiérrez OM, Muntner P, Rizk DV, McClellan WM, Warnock DG, Newby PK, Judd SE. Dietary patterns and risk of death and progression to ESRD in individuals with CKD: a cohort study. Am J Kidney Dis. 2014;64:204-13.

13. Yu W, Luying S, Haiyan W, Xiaomei L. Importance and benefits of dietary sodium restriction in the management of chronic kidney disease patients: experience from a single Chinese center. Int Urol Nephrol. 2012;44:549-56.

14. Michishita R, Matsuda T, Kawakami S, Kiyonaga A, Tanaka H, Morito N, Higaki $Y$. The association between unhealthy lifestyle behaviors and the prevalence of chronic kidney disease (CKD) in middle-aged and older men. J Epidemiol. 2016;26:378-85

15. Michishita R, Matsuda T, Kawakami S, Kiyonaga A, Tanaka H, Morito N, Higaki $Y$. The accumulation of healthy lifestyle behaviors prevents the incidence of chronic kidney disease (CKD) in middle-aged and older males. Environ Health Prev Med. 2016;21:129-37.

16. Michishita R, Matsuda T, Kawakami S, Tanaka S, Kiyonaga A, Tanaka H, Morito N, Higaki Y. The association between the changes in lifestyle behaviors and the incidence of chronic kidney disease (CKD) in middleaged and older men. J Epidemiol. 2017;27:389-97.

17. Ornish D, Scherwitz LW, Billings JH, Brown SE, Gould KL, Merritt TA, Sparler S, Armstrong WT, Ports TA, Kirkeeide RL, Hogeboom C, Brand RJ. Intensive lifestyle changes for reversal of coronary heart disease. JAMA. 1998;280:2001-7.

18. Japanese Society of Nephrology. Evidence-based clinical practice guideline for CKD 2013. Clin Exp Nephrol. 2014;18:346-423.

19. Kashiwagi A, Kasuga M, Araki E, Oka Y, Hanafusa T, Ito H, Tominaga M, Oikawa S, Noda M, Kawamura T, Sanke T, Namba M, Hashiramoto M, Sasahara T, Nishio Y, Kuwa K, Ueki K, Takei I, Umemoto M, Murakami M, Yamakado M, Yatomi Y, Ohashi H, Committee on the Standardization of Diabetes Mellitus-Related Laboratory Testing of Japan Diabetes Society. International clinical harmonization of glycated hemoglobin in Japan: from Japan Diabetes Society to National Glycohemoglobin Standardization Program values. J Diabetes Investig. 2012;3:39-40.

20. Hoelzel W, Weykamp C, Jeppsson JO, Miedema K, Barr JR, Goodall I, Hoshino T, John WG, Kobold U, Little R, Mosca A, Mauri P, Paroni R, Susanto F, Takei I, Thienpont L, Umemoto M, Wiedmeyer HM, IFCC Working Group on HbA1c Standardization. IFCC reference system for measurement of hemoglobin $A_{1} C$ in human blood and the national standardization schemes in the United States, Japan, and Sweden: a method-comparison study. Clin Chem. 2004;50:166-74.

21. Tajima N, Noda M, Origasa H, Noto H, Yabe D, Fujita Y, Goto A, Fujimoto K, Sakamoto M, Haneda M. Evidence-based practice guideline for the treatment for diabetes in Japan 2013. Diabetol Int. 2015;6:151-87.

22. Matsuo S, Imai E, Horio M, Yasuda Y, Tomita K, Nitta K, Yamagata K, Tomino Y, Yokoyama H, Hishida A, Collaborators developing the Japanese equation for estimated GFR. Revised equations for estimated GFR from serum creatinine in Japan. Am J Kidney Dis. 2009;53:982-92.

23. Coresh J, Turin TC, Matsushita K, Sang Y, Ballew SH, Appel L, Arima H, Chadban SJ, Cirillo M, Djurdjev O, Green JA, Heine GH, Inker LA, Irie F, Ishani A, Ix JH, Kovesdy CP, Marks A, Ohkubo T, Shalev V, Shankar A, Wen CP, de Jong PE, Iseki K, Stengel B, Gansevoort RT, Levey AS, CKD Prognosis
Consortium. Decline in estimated glomerular filtration rate and subsequent risk of end-stage renal disease and mortality. JAMA. 2014;311:2518-31.

24. Anavekar NS, McMurray JJ, Velazquez EJ, Solomon SD, Kober L, Rouleau JL, White HD, Nordlander R, Maggioni A, Dickstein K, Zelenkofske S, Leimberger JD, Califf RM, Pfeffer MA. Relation between renal dysfunction and cardiovascular outcomes after myocardial infarction. N Engl J Med. 2004;351:1285-95

25. Matsuo K, Inoue T, Node K. Estimated glomerular filtration rate as a predictor of secondary outcomes in Japanese patients with coronary artery disease. J Cardiol. 2009;53:232-9.

26. Harrison NA, Rainford DJ, White GA, Cullen SA, Strike PW. Proteinuria-what value is the dipstick? Br J Urol. 1989;63:202-8.

27. Ministry of Health, Labour and Welfare. Standardized health check-up and intervention program, 2007. http://www.mhlw.go.jp/bunya/kenkou/seikatsu/ pdf/02.pdf (Accessed 23 Dec 2014), (in Japanese).

28. Kohro T, Furui Y, Mitsutake N, Fujii R, Morita H, Oku S, Ohe K, Nagai R. The Japanese national health screening and intervention program aimed at preventing worsening of the metabolic syndrome. Int Heart J. 2008;49:193-203.

29. Kodama S, Saito K, Tanaka S, Maki M, Yachi Y, Asumi M, Sugawara A, Totsuka K, Shimano H, Ohashi Y, Yamada N, Sone H. Cardiorespiratory fitness as a quantitative predictor of all-cause mortality and cardiovascular events in healthy men and women: a meta-analysis. JAMA. 2009:301:2024-35.

30. Koba S, Tanaka H, Maruyama C, Tada N, Birou S, Teramoto T, Sasaki J. Physical activity in the Japan population: association with blood lipid levels and effects in reducing cardiovascular and all-cause mortality. J Atheroscler Thromb. 2011:18:833-45.

31. Ikeda N, Inoue M, Iso H, Ikeda S, Satoh T, Noda M, Mizoue T, Imano H, Saito E, Katanoda K, Sobue T, Tsugane S, Naghavi M, Ezzati M, Shibuya K. Adult mortality attributable to preventable risk factors for non-communicable diseases and injuries in Japan: a comparative risk assessment. PLoS Med. 2012:9:e1001160.

32. Wahid A, Manek N, Nichols M, Kelly P, Foster C, Webster P, Kaur A, Friedemann Smith C, Wilkins E, Rayner M, Roberts N, Scarborough $P$. Quantifying the association between physical activity and cardiovascular disease and diabetes: a systematic review and meta-analysis. J Am Heart Assoc. 2016;5:e002495

33. Tominaga M, Equchi H, Manaka H, Igarashi K, Kato T, Sekikawa A. Impaired glucose tolerance is a risk factor for cardiovascular disease, but not impaired fasting glucose. The Funagata Diabetes Study. Diabetes Care. 1999;22:920-4

34. Dunkler D, Kohl M, Teo KK, Heinze G, Dehghan M, Clase CM, Gao P, Yusuf S, Mann JF, Oberbauer R, ONTARGET Investigators. Population-attributable fractions of modifiable lifestyle factors for CKD and mortality in individuals with type 2 diabetes: a cohort study. Am J Kidney Dis. 2016;68:29-40.

35. Ricardo AC, Anderson CA, Yang W, Zhang X, Fischer MJ, Dember LM, Fink JC, Frydrych A, Jensvold NG, Lustigova E, Nessel LC, Porter AC, Rahman M, Wright Nunes JA, Daviglus ML, Lash JP, CRIC Study Investigators. Healthy lifestyle and risk of kidney disease progression, atherosclerotic events, and death in CKD: findings from the Chronic Renal Insufficiency Cohort (CRIC) Study. Am J Kidney Dis. 2015;65:412-24.

36. Nagasawa $Y$, Yamamoto $R$, Shinzawa $M$, Hasuike $Y$, Kuragano $T$, Isaka $Y$, Nakanishi T, Iseki K, Yamagata K, Tsuruya K, Yoshida H, Fujimoto S, Asahi K, Moriyama T, Watanabe T. Body mass index modifies an association between self-reported regular exercise and proteinuria. J Atheroscler Thromb. 2016:23:402-12.

37. Manson JE, Greenland P, LaCroix AZ, Stefanick ML, Mouton CP, Oberman A, Perri MG, Sheps DS, Pettinger MB, Siscovick DS. Walking compared with vigorous exercise for the prevention of cardiovascular events in women. $\mathrm{N}$ Engl J Med. 2002;347:716-25

38. Lee DC, Sui X, Artero EG, Lee IM, Church TS, McAuley PA, Stanford FC, Kohl HW 3rd, Blair SN. Long-term effects of changes in cardiorespiratory fitness and body mass index on all-cause and cardiovascular disease mortality in men: the Aerobics Center Longitudinal Study. Circulation. 2011;124:2483-90. 